Article

\title{
Integrating Gamification and Social Interaction into an AR-Based Gamified Point System
}

\author{
Boyang Liu *(i) and Jiro Tanaka *(1) \\ Graduate School of Information, Production and Systems, Waseda University, 2-7 Hibikino, Wakamatsu Ward, \\ Kitakyushu, Fukuoka 808-0135, Japan \\ * Correspondence: waseda-liuboyang@moegi.waseda.jp (B.L.); jiro@aoni.waseda.jp (J.T.)
}

Received: 29 June 2020; Accepted: 11 August 2020; Published: 13 August 2020

\begin{abstract}
A loyalty program is an important link between consumers and merchants in daily consumption. While new technologies (e.g. gamification, social networks, augmented reality, and so on) make it possible to strengthen this bond, their potential has not yet been fully exploited. In our research, we explore a novel approach to integrate gamification and social interaction into a loyalty program based on augmented reality (AR). We propose an AR-based gamified point system which supports users in obtaining pet-based dynamic feedback on mobile devices and provides a multi-user environment for social interaction. Compared to traditional point systems, pet-based designs help to establish an emotional connection between users and the system. The multi-user environment is designed to increase the user's motivation through the positive effects of social interactions. Our system provides interpersonal communication channels between users, including competitive and non-competitive interactions. We performed an evaluation consisting of two experiments to examine the effects of game elements (mission and feedback) and social cues (competitive and non-competitive interactions). In the first experiment, we analyze the change in online shopping behavior before and after adding game elements. The results show that gamification can increase user participation in online shopping. In the second experiment, we study the effects of social cues. The results show that social cues can motivate users to participate in the use of a gamified point system.
\end{abstract}

Keywords: gamification; game-based marketing; motivation; user engagement; multi-user interaction; social incentive; augmented reality

\section{Introduction}

Loyalty programs are structured marketing strategies, designed by merchants to encourage people to continue to shop at or use the services of businesses associated with the program [1]. They are effective at retaining customers by preventing them from turning to competitors and can also maximize the lifetime value of a customer by offering incentives to spend more and buy more often [2-6]. Successful customer loyalty programs are win-wins for brands and consumers [4,7].

Loyalty marketing began long ago, with the use of paper cards which graduated into plastic card-based systems [8,9]. A point system is the most common loyalty program methodology [10]. Businesses issue physical point cards to their loyal customers, in order to encourage them to make repeated purchases and earn rewards points through the point system [11-13]. These points can be redeemed for discount or a special offer later. However, in plastic card-based systems, interaction with the system is usually very limited [14]. Stamp card-based loyalty programs make use of paper cards that need to be stamped every time a customer makes a purchase, such that users can easily check the progress of stamp accumulation. The problem is that stamp card-based loyalty programs lack support for customer data analysis, which means that marketing and rewards cannot be targeted [15-17]. 
As consumers began to embrace mobile devices and social media, it became increasingly important for merchants to effectively incorporate smart phones into loyalty programs [18,19]. A very important feature is that smart phone-based loyalty systems can easily meet the social needs of users, which can solve the problem that plastic-card based loyalty programs or stamp cards cannot facilitate linkage to social channels [17,18]. Furthermore, smart phone-based AR applications, such as pokémon go [20], provide users with new experiences that provide perception beyond the real world. With the help of advanced AR technologies, information about the surrounding real world of the user becomes interactive and digitally manipulated [21]. In addition, using gamification to establish an emotional connection between consumers and merchants has been considered as a fascinating and innovative marketing tactic [22-25]. The idea is to add game elements to the loyalty program, in order to engage customers and encourage them to participate. Essentially, it is an opportunity to create a memorable customer experience and strengthen their emotional connection [26].

We consider solving the following deficiencies: (1) uncertain user-system connection. A loyalty program rewards the consumption of users through financial incentives, but rarely consider their motivation and emotional needs; (2) insufficient social connection. The main social loyalty actions include referring friends and sharing a brand or product with friends through social media. However, these actions are only one-time sharing activities and cannot facilitate long-term social connections. Furthermore, social media and loyalty programs are not tightly coupled, which may weaken the impact of social connection.

In our research, we explore a novel approach to integrate gamification and social interaction into a point system based on AR to solve these problems. The gamification part is a supplement to the current point system structure. Our methodology includes: (1) using gamification to create mission frameworks that satisfy the motivations of different users and to build emotional connections between users and the system with a pet-based design. New input (i.e., mission) is added into the gamified point system. Users can complete the mission according to their own preferences. To reward the completion of mission, new feedback is designed as reward, including value point, pet and virtual food. The user gets value points and upgrade the level after completing the mission. Value point can be used to purchase virtual food and help pets recover energy in the system. In the end, the income, expenditure, and feeding of the pet create a positive cycle. The desire to take care of a virtual pet may facilitate and sustain the motivation for using the system, which can establish an emotional connection between the user and the system; (2) Social impact is tightly coupled into the point system to establish long-term connections between users. Based on these game elements, our system provides channels for interpersonal communication (i.e., competitive and non-competitive interactions), which allows users to engage in long-term interactions without binding social media. Users can interact with each other by competing with pets or giving away virtual food in this system. We performed two experiments to examine the effects of game elements and social cues. In the first experiment, we analyze the change in online shopping behavior before and after adding game elements. In the second experiment, we study the effects of social cues by using the same game elements.

In this paper, we introduce the detailed system design and implementation of the gamified point system. Mobile devices and a physical point card are used together and AR is used to superimpose game elements onto the card, allowing users to interact with pets. A physical point card is used to identify the card holder as a participant in the program [9]. We evaluate our system to explore how game designs influence user behavior and the impact of social cues on system usage. We believe that our research provides inspiration for the design of gamified systems and their potential applications.

The remainder of this paper is organized as follows. Section 2 describes the related work in the literature. Sections 3 and 4 describe the design and implementation of our system. Section 5 describes the experiment and evaluates the results of our system. In Section 6, we summarize the findings of this research. In Section 7, we discuss the current study limitations and details of future studies. Finally, in Section 8, we conclude the paper. 


\section{Related Work}

In this section, we describe related work in the areas of pet-based gamified systems, social incentives, and augmented reality games.

\subsection{Pet-Based Gamified Systems}

Chen et al. [27] studied how to portray open learner models as animal companions, in order to motivate children to learn in a digital classroom environment. To meet the two challenges of motivation and interactivity for open learner models, the concept of open learner models as animal companions was proposed based on the emotional attachment of humans towards pets. Liao et al. [28] proposed a system named My-Mini-Pet. It was a handheld pet-nurturing game environment, in which students learn with an animal learning companion, their My-Mini-Pet. The results showed that these strategies were effective, encouraging students to engage in learning activities. Furthermore, the game attracted their attention and stimulated discussion between peers. Yang et al. [29] developed an Energy Conservation PET (ECOPET) system using a game-based learning strategy. The results demonstrated that the system significantly promoted the self-awareness, learning motivation, as well as willingness to conserve energy of learners. Orland et al. [30] implemented and tested the effectiveness of a virtual pet game designed specifically for energy use reduction in a commercial office setting. The results demonstrated that game participants decreased their plug load energy consumption and most of them indicated that the game helped them be more energy conscious.

These gamified systems all use pet-based designs to create emotional bonds with users and influence user behavior. Inspired by these studies, we have attempted to combine point system and pet-based designs to establish emotional connections between users and the system, as well as to positively influence consumer spending choices.

\subsection{Social Incentives}

Chen et al. [31] presented findings from a two-month comparative study that utilized a social fitness application called Healthy Together. The results showed that social fitness application design for patients should take into account their need for support from social incentives. Rokicki et al. [32] studied various alternatives for reward distribution strategies in crowdsourcing, compared to the commonly used pay-per-task approach. These strategies were based on competitive and randomized aspects. The evaluation showed that these strategies promoted substantial performance improvements in the crowdsourcing scenarios studied, compared to the baseline. Li et al. [33] designed a multiplayer software tutorial system called CADament. Compared with existing software tutorial systems, their system generated an engaging learning experience through competition. Their study showed that their system resulted in better performance over pre-authored tutorials by improving learner performance, increasing motivation, and stimulating knowledge transfer. Park et al. [34] presented a novel crowdsourcing method, where several design teams made up of designers and crowd compete with each other. They observed that the elements of competition and collaboration helped to sustain the crowd's motivation to participate, and that quality design outcomes were produced with a higher level of satisfaction for the stakeholders.

Social incentives have been proven to play an important role in the above studies. We also use them in our system to increase user engagement. Our research studies the impact of social incentives in two different types of interaction: competition and sharing.

\subsection{Augmented Reality Systems}

Pokémon Go is a 2016 AR mobile game developed and published by Niantic in collaboration with The Pokémon Company for iOS and Android devices [20]. It uses the mobile device's GPS to locate, capture, battle, and train virtual creatures, called Pokémon, which appear as if they are in the player's real-world location. This method of combining AR virtual creatures and the real world provides a 
reference for the AR pet-based design in our research. Allen et al. [35] showed their workflow in making a 3D virtual pet game, starting from completing the concept, making 3D models, scripting, and integrating $\mathrm{AR}$ as the main feature to provide a unique experience in simulating a pet-raising scenario on a mobile device. Their study provides a reference in this work for how to build a virtual pet game, as we adopted the theme of pet-raising games in our research. Hwang et al. [36] proposed a competitive gaming approach to support AR-based learning activities conducted in real-world contexts. Their experimental results showed that AR-based gaming approaches can improve not only the learning attitudes of students, but also their learning performance. Their work combined competition with AR and demonstrated that such a strategy can inspire user interest. Bai et al. [37] presented an AR system designed for young children to enhance their social pretend play. Observations showed that children were highly engaged with the AR system. Although this study was designed to support cognitive and social development in early childhood, it provided reference for how to build a co-located social AR framework. Wetzel et al. [38] presented a set of design guidelines for designing augmented reality games, drawn from the experiences of three mixed reality games. These guidelines provide specific guidance on relationships between real and virtual space, social interactions, the use of AR technologies, and maintaining consistent themes. Some guidelines, such as "stick to the theme" and "keep it simple" gave us some instruction in our design. Jin et al. [39] proposed a programming tool designed for children with AR technology. Their found that children gained confidence and interest as they learned computer concepts easily from a maze game with AR real-time feedback. Therefore, we believe that AR-based feedback methods may stimulate user interest and provide a new experience for users. Bakker et al. [40] proposed an AR mobile game that aims to provide a fun and engaging social experience. In this game, players compete and co-operate with teammates to build virtual blocks. Their research combines different social interactions with AR mobile games, which is similar to our system.

Our system was implemented based on AR. The design of these AR systems or games provided reference when we designed our prototype system.

\section{System Description}

The system features an AR pet (i.e., an animal companion), with the aim of evoking the caring nature of users. Our gamified point system provides an interchange between shopping in the real world and pet-raising in the virtual world.

\subsection{Single-User Interaction}

In the single-user interaction (see Figure 1), the mission is a new input. After completing the mission, users will get pet-based feedback.

\subsubsection{Game Element-Mission}

The mission aims to remind users of multi-value creation in shopping. Multi-value creation refers to the value that users create in shopping, such as environmental and social impacts. The mission was designed as traditional point systems only reward a user's consumption, rather than considering the user's purchase motivation. The main purpose of the mission is to encourage different purchase motivations to meet their needs, thereby promoting sustainable consumption and healthy living.

When the system is turned on, the system will display the main interface. The user can view the mission through the button linked to the mission interface on the main interface. In the mission interface, missions are displayed in text form (see Figure 2). Users can browse the mission interface to view the content of mission when shopping, and view the number of completed mission after shopping. In order to motivate users to complete mission, we designed a virtual environment based on AR pet in the system. If users complete the mission, they will get feedback in the virtual environment. The content of the mission is set to be related to shopping, such as purchasing products that meet a certain requirement. When a user chooses to purchase a product that meets this requirement, the mission will be deemed completed. On the contrary, if there is no product that meets this 
requirement among the products purchased by the user, the mission is considered to have not been completed. Users can freely choose the mission they want to complete during shopping according to their preferences. If the mission is failed, users will not receive rewards.

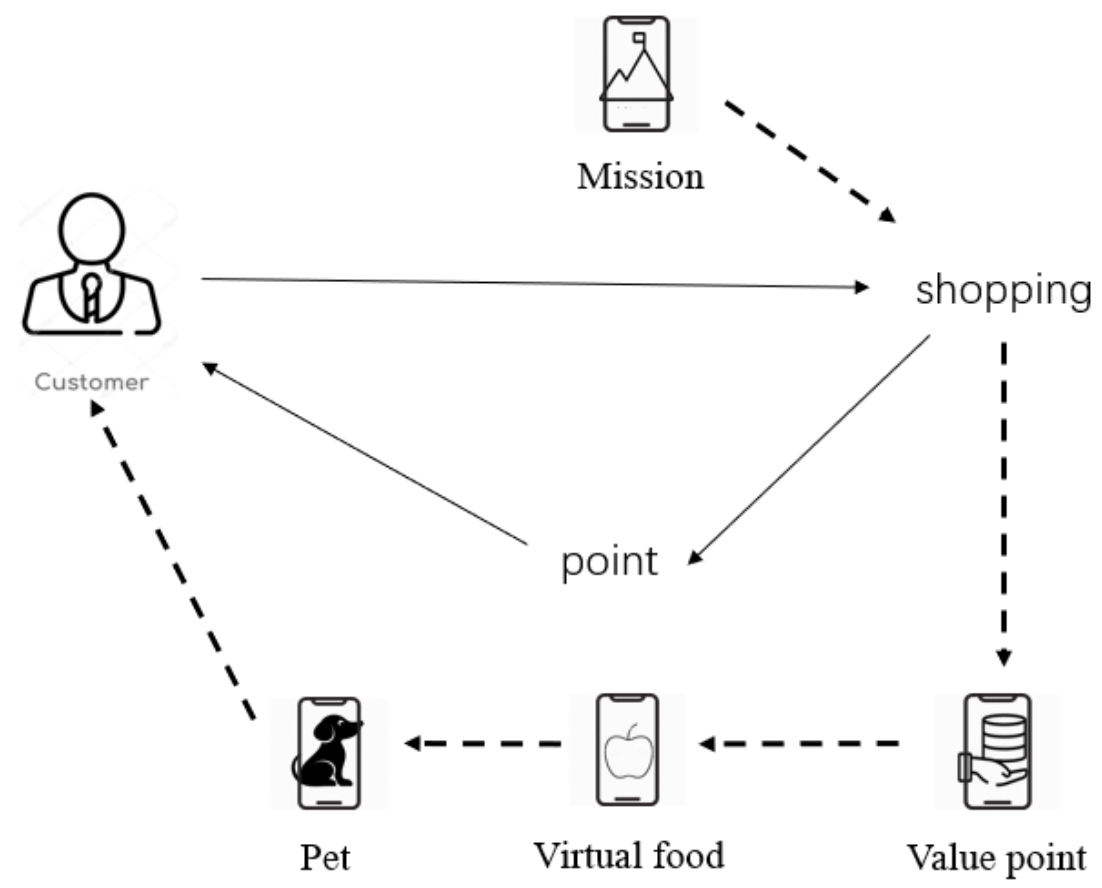

Figure 1. Single-user interaction. The solid line represents the traditional point system structure. After shopping, customers get points as feedback for shopping. The gamified point system adds the design of game elements (dotted lines) to the traditional point system structure. Users can browse the mission of value creation during shopping. A value point provides feedback after completing a mission in shopping and can be used to redeem virtual food. Virtual food can then be used to feed the pet.

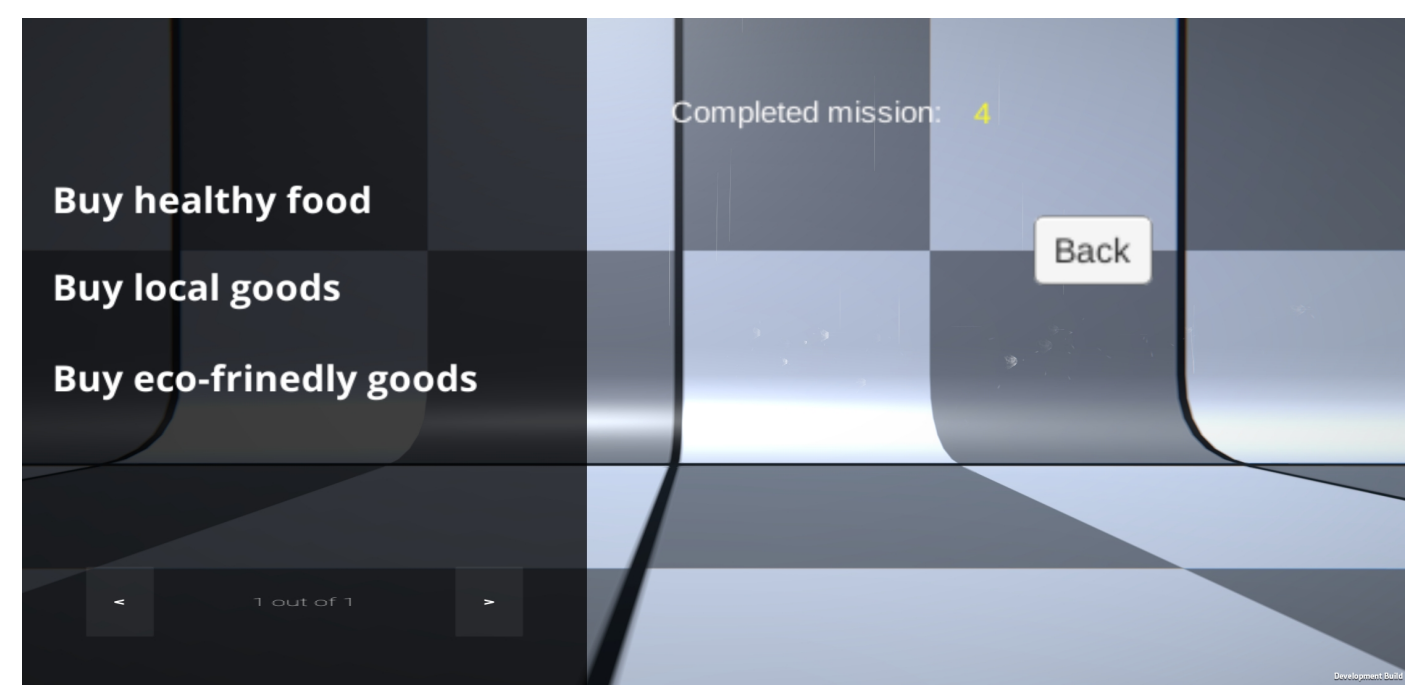

Figure 2. Mission interface. The left side shows the daily mission, and the upper right corner shows the number of mission completed.

\subsubsection{Game Element-Feedback}

(1) Value Point If the user has completed the mission, they can obtain value points after shopping. Value points can be used to purchase virtual food in the virtual environment (see Figure 1). 
(2) Pet In the system, every user can feed a virtual pet. The pet reflects the user's status in the virtual environment. A pet has important attributes including level and energy. The level reflects the long-term status of the user and the energy is the feedback for the short-term participation. The pet gains an experience value (EXP) after a user completes a mission. If the EXP of the pet reaches a certain threshold, the pet will level up. Pets gradually lose energy. In order to keep the pet energetic, the user needs to feed the pet.

(3) Virtual Food Virtual food is used to help pets recover energy and can be given to other users as a gift. The food given by others can also be used to restore the energy of the pet.

After shopping, users can enter the value point and pet interface from the main interface. In the value point and pet interface, the user needs to point the phone camera at a physical card, in order to interact with the pet or to see the value points, as they will be superimposed onto the card (see Figure 3).

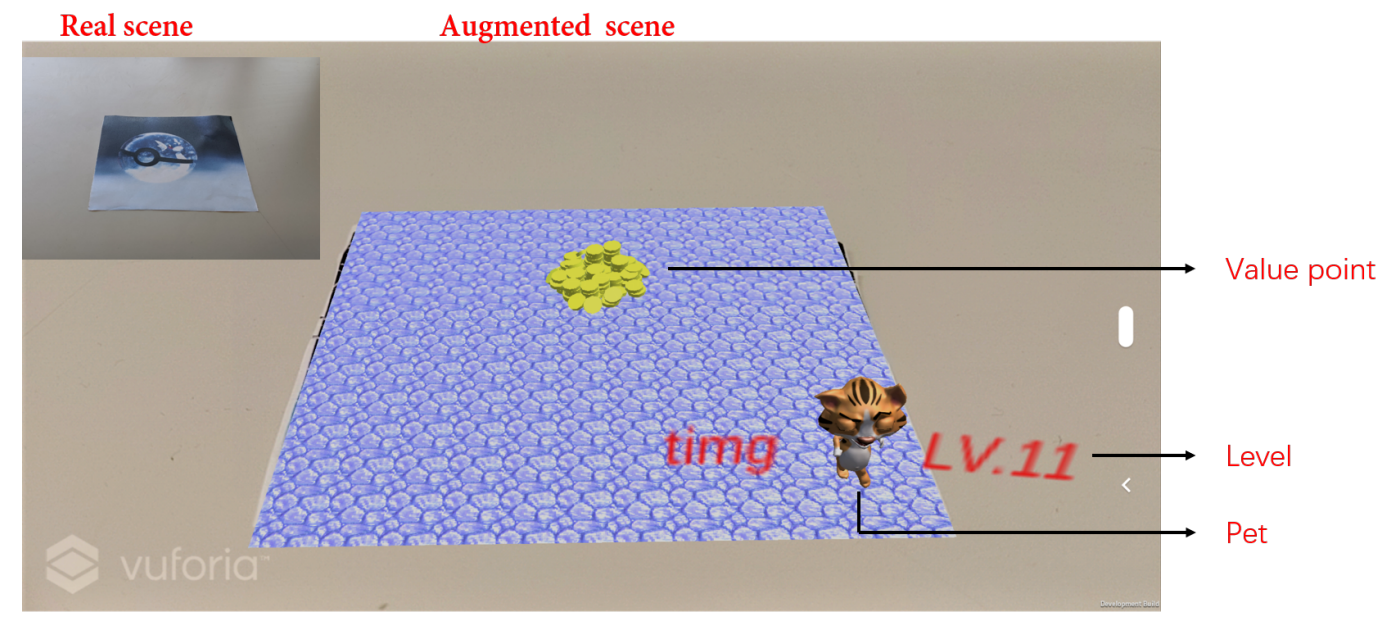

Figure 3. Value point and pet interface. The AR information is superimposed onto the physical point card.

The size of the value point will vary, depending on the quantity. The level and user name are displayed near the pet. The pet gradually loses energy and its movement changes accordingly, in order to remind the user to feed the pet.

If the user completes mission, the value point increases. The user can click on value points to exchange for virtual food. After exchange, the value points are consumed and decreased. Virtual food will be displayed around the value points. By clicking on the virtual food, it will be consumed and the pet will immediately recover a certain amount of energy and give action feedback accordingly.

\subsection{Multi-User Interaction}

\subsubsection{Competitive Interaction}

In a competitive interaction, users can compete with other users through their pets. We designed user interfaces for competitive interaction across the network. Users willing to participate in the competitive interaction will be included in a name list, which is considered to allow other users to access their level information. The user can view the name list of users and choose rivals to compete (see Figure 4). The design of competitive interaction is asynchronous. That is, when one user participates in the interaction, other users do not need to attend the interaction at the same time. According to the user's choice, the system will instantiate the pets of rivals to compete. It ensures that users can get feedback through competitive interaction at any time.

When the user enters the competitive interaction interface from the main interface, a room will be created, and the user's pet will be instantiated in the middle of the room automatically without 
manual control by the user. After that, the user can click the button in the upper right corner of the competitive interaction interface to browse the list of rivals. We adopt a continuous competition mode instead of a turn-based mode. Users can choose any number of rivals to compete. The maximum number of users participating in the competitive interaction includes the user and all rivals in the list. There is no limit to the number of rivals. In current system, we set the number to four. The pets of the selected rivals will be automatically instantiated next to the user's pet. In the current competitive interaction, users who win the game will not get rewards, because we want to know whether the competitive interaction itself will bring internal motivation without external incentives such as point or value point.

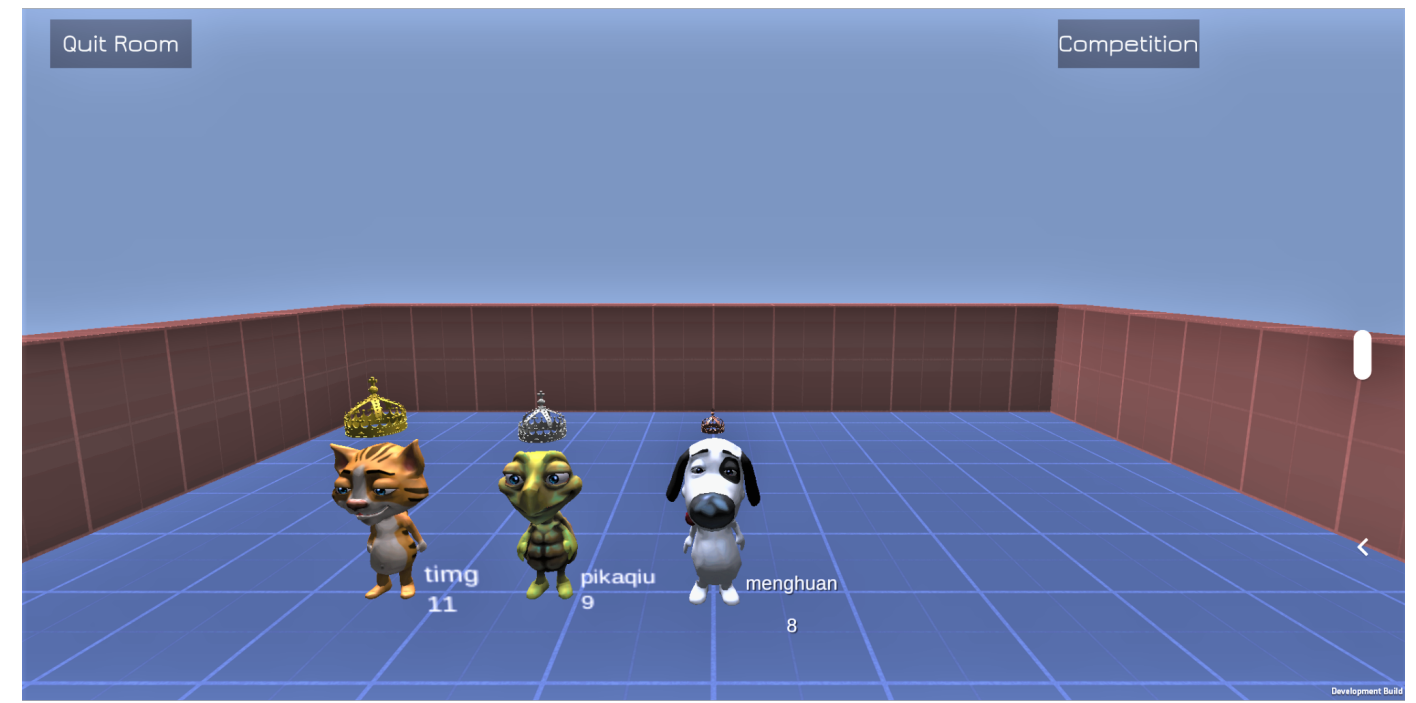

Figure 4. Competitive interaction interface. The pet with highest level will wear a gold crown, while the pet with the second highest level will have a silver crown, and pet with the third highest level will have a bronze crown.

\subsubsection{Non-Competitive Interaction}

In the non-competitive interaction interface (see Figure 5), users can share their food to other users. The user can enter the non-competitive interaction interface from the main interface by clicking the button linked to the interface. The interface is very similar to the value point and pet interface. The user also clicks on the value points to purchase virtual food. However, when the virtual food is clicked, the virtual food will not be consumed but a user list will pop up. The user can select the recipient of the gift from the name list and send the gift. After that, the food disappears. When the recipient uses the system and opens the non-competitive interaction interface, the recipient can see the virtual food displayed next to the pet. The recipient can choose to use it to feed the pet in the value point and pet interface, or continue to give it to another user. Similar to the design of competitive interaction, users will not get additional rewards when they give the virtual food to other users, because we want to know whether non-competitive interaction itself will bring motivation. In our research, the main reason we separate this interface from value point and the pet interface is that we want to study the difference between a single-user game environment and a multi-user environment. Therefore, in the actual deployment situation, the interface can be unified with the value point and pet interface, and various methods can be used to realize pet feeding and gift giving functions. For example, long-pressing the selected food and dragging it to the pet will trigger the pet feeding function, and clicking on the food will pop up a name list to allow the user to give it away. 


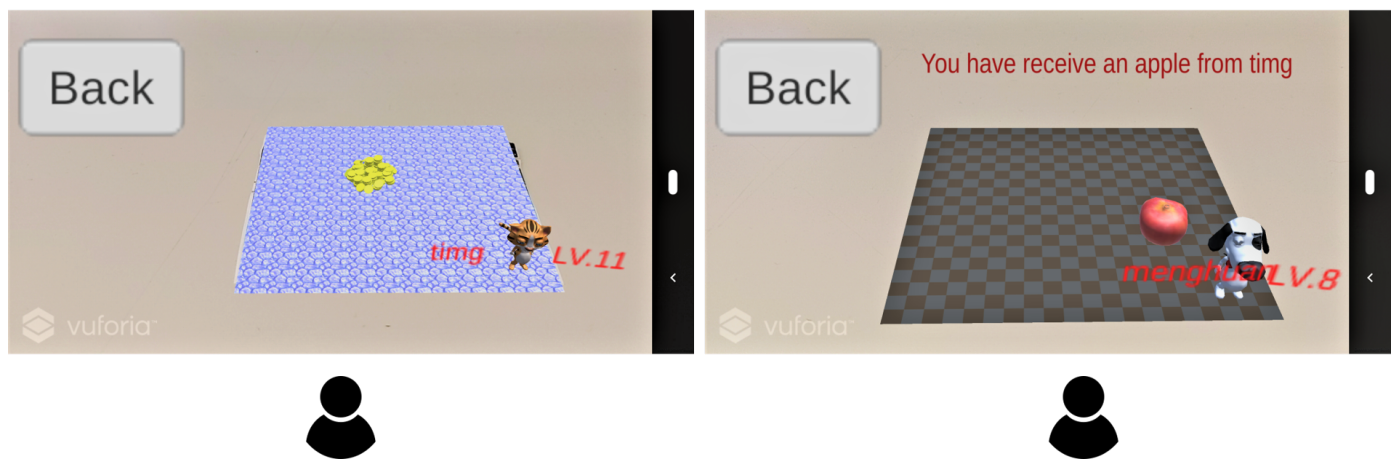

Figure 5. Non-competitive interaction interface. User timg gave an apple to user menghuan.

\section{System Implementation}

To realize this multi-user system, we used a client-server network architecture. Users can participate using a mobile device. Every client connected to the server constantly receives data, locally creating a representation of the game state. If a client performs an action, that information will be sent to the server. The server checks whether the information is correct, then updates its game state. After that, it propagates this information to all clients.

The main hardware devices used for development of the prototype system included a laptop and smartphones. The laptop was used to build the system and works as the server. Smartphones were the mobile devices used to install the client. Windows 10 Home Edition was installed on the laptop. The processor was an Intel(R) Core(TM) i7-6500U CPU @2.50 GHz, and the laptop had 8 GB RAM. The development software was Unity 2019.2.11f1 (64-bit), a cross-platform game engine [41]. Unity 3D was used to build and render the AR system. The Vuforia SDK was used for the AR implementation. We deployed ARCamera into the scene and activated the target databases. We added five targets to the target database; that is, up to five users can use their own physical point card to use the gamified point system. Increasing the number of targets will allow more users to participate. Photon Unity Networking was used to implement the competitive interaction [42]. For the server, we deployed WampServer Version 3.0.6 32 bit, consisting of the Apache web server, OpenSSL for SSL support, and MySQL database. Apache and MySQL were kept running on the laptop. Communication between Unity 3D and MySQL was implemented in the PHP programming language. We used the WWW and WWWForm classes to send and receive requests between Unity and the server. When receiving from the database, the information was converted into JSON format and received. After receiving, it was decoded into a string format.

\section{Evaluation}

\subsection{Experiment 1}

\subsubsection{Purpose}

To evaluate the gamified system, we conducted an online shopping simulation experiment using a within-subjects design. The purpose of this experiment was to study the effects of game elements on user shopping behavior.

\subsubsection{Participants}

Six student volunteers (three of which were female), including five laboratory students, between the ages of 20 and 26 participated in this experiment $(M=22.8)$. They were not informed in advance of the purpose of the experiment and the systems to be used. All participants had experience using the traditional point system (i.e., obtaining certain points after shopping) before the experiment. All participants reported having played at least one multiplayer video game before. 


\subsubsection{Conditions}

There were 3 conditions in the experiment 1 . Condition 1 was to use the traditional point system for shopping. In the system, users can obtain a certain percentage of points according to the price of the purchased products. The user opened the shopping website to conduct shopping experiment through the button built into the system, and returned to the system to check the number of points after completing the shopping. Condition 2 was to use a point system with mission and text information added for shopping. Text information was a textual representation of the number of mission completed in the mission interface. The user viewed the mission before browsing the web for shopping experiment, and checked the number of completed mission and points after completing the shopping. Condition 3 was to use a gamified point system, which added mission, text and AR feedback. Users can view the content of mission before shopping. After shopping, users can not only check the number of points and completed mission in text form, but also gain game experience by interacting with AR feedback. The experiment was carried out in a controlled setting environment.

To sum up, the only difference between condition 1 and condition 2 was the mission and the text that showed the number of mission completed. The only difference between condition 2 and condition 3 was whether there was AR game feedback. Therefore, by comparing condition 1 and condition 2, we can understand the impact of mission on user shopping without AR-based feedback. By comparing condition 2 and condition 3, we can understand the impact of AR-based feedback. We expect that feedback will be the main factor affecting user engagement.

\subsubsection{Procedure}

To conduct the study, six participants performed three conditions, each for five days. In order to explore the impact of the gamified system on shopping, we have added a shopping site to the experimental systems to facilitate users to conduct experiments. Under all conditions, the structure and content of the website are the same. There were 180 products on the shopping site, which were divided into 14 categories. The number of products in each category was 5-19. Among the 180 products, there were a total of 15 healthy foods, 15 local products, and 19 environmentally friendly products. Users made purchases from all products every day. Healthy food was a separate category (included in 14). Environmentally friendly products carried the word "eco" in their names and were classified as a separate category (included in 14). Local products had the word "fukuoka" in their names. The website has a 3-level structure. Level 1 shows all the categories. Level 2 shows the products with name inside each category. Level 3 shows the detailed information about the product. Therefore, users can easily find products that meet the mission requirement. All participants were given a brief introduction of the system for approximately $5 \mathrm{~min}$ and the basic operating procedures for approximately $10 \mathrm{~min}$ before each condition (see Figure 6). The introduction includes instructions on the system and shopping website under experimental conditions. Then, the recorded video of using the system for shopping will be played to introduce how to use the system to do online shopping. After that, participants can use the system to experience by themselves. At the scene, a researcher acted as an instructor, answering questions from participants and helping them to familiarize themselves with the system.

In the first five days, all users conducted online shopping experiments using the traditional point system (condition 1). After the purchase was completed, their points were updated. In the second five days, all users used the system with mission and textual information (condition 2). Pre-defined missions were designed, based on sustainable consumption [43] (i.e., the purchase of environmentally friendly goods, the purchase of healthy foods, and the purchase of local goods). To complete a mission, the users needed to choose the corresponding category (environment-friendly, local, or healthy). Each mission could be completed multiple times. The users could see how many missions had been completed through textual information. In the third five days, all users used the system with missions, textual information, and pet-based feedback (condition 3 ). The content and completion of the mission were the same as for condition 2 . Under each condition, a researcher acted as a mentor to help the experimenters solve problems during the experiment. At the end of the daily 
experiment, the researcher confirmed the user's shopping situation and entered the appropriate data into the database to update the user's game state. Under all conditions, users were free to choose products, and there was no mandatory requirement for the completion of mission.

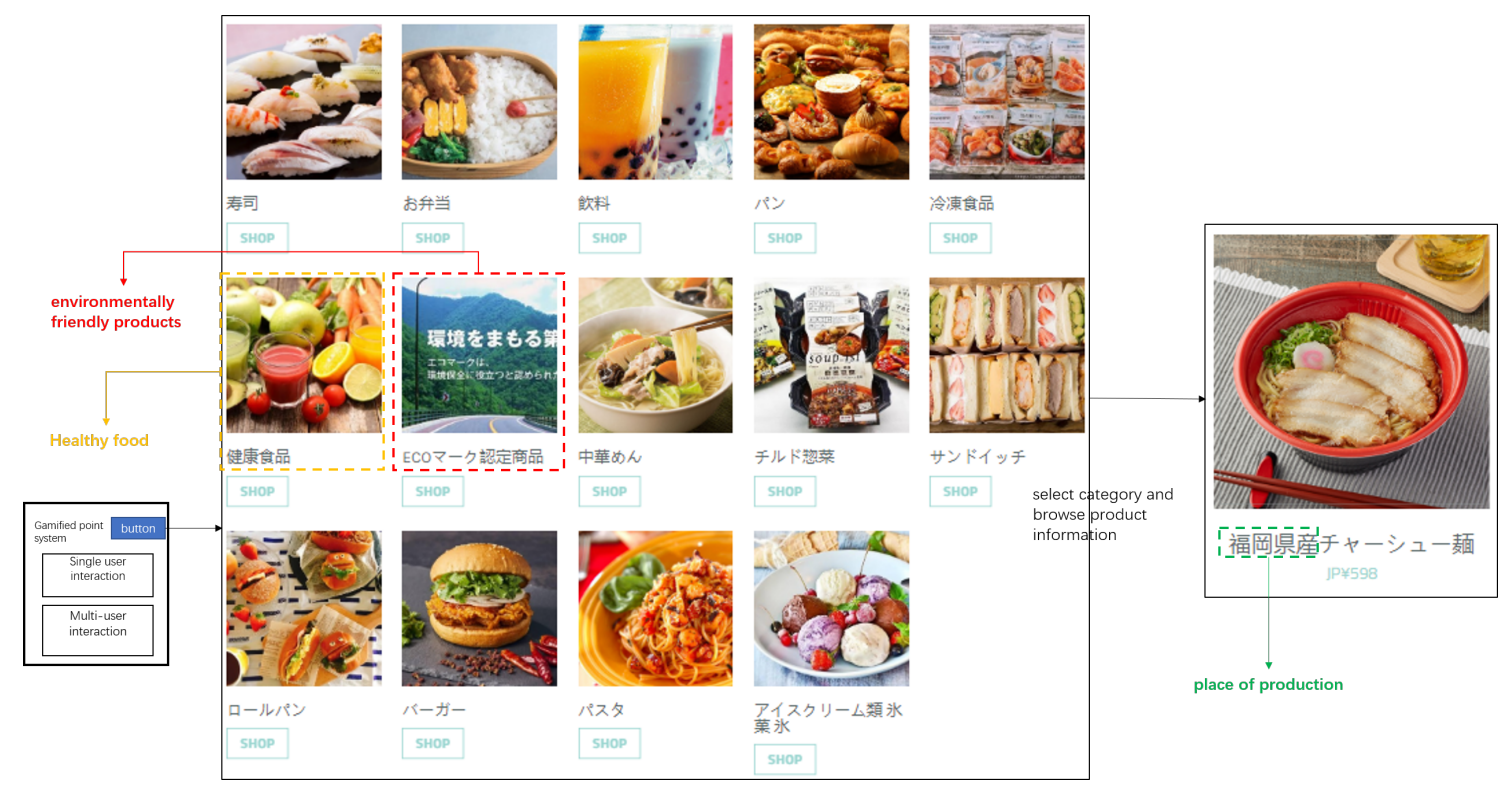

Figure 6. Online shopping experiment process. Users access shopping websites through links built in the gamified point system. The shopping website contains 14 categories of products. After entering the sub-interface, the user can view specific product information and then select the product to purchase. The figure shows the level 1 interface of the website and the name of one product in the level 2 interface. Categories include sushi, bento, drinks and more. The right side shows noodles produced in Fukuoka Prefecture.

Google Analytics was used to record user behavior data during online shopping experiments, including average session duration [44], pages per session [44], items purchased, and their quantity.

\subsubsection{Results}

\section{(1) Online Shopping Engagement Pages Per Session:}

One way of measuring interest in the content is pages per session. From a business perspective, the higher the pages per session metric, the better [44]. This is because a high pages per session count shows that the website visitors looked around and visited more than one page-truly engaging with the website.

In the experiment, a session was a one-day online shopping experiment. We calculated the number of pages per session [45] in the three conditions (see Figure 7). In condition 1, the average pages per session per person was $29.4(\mathrm{SD}=10.5)$; in condition 2 , the average pages per session per person was $41.1(\mathrm{SD}=24.4)$; and, in condition 3 , the average pages per session per person was $46.5(\mathrm{SD}=27.7)$.

We used the paired t-test [46] to compare the pages per session between the conditions. The results showed that there was no significant difference in average pages per session between conditions 1 and $2(p=0.06)$. However, there were significant differences between conditions 2 and $3(p=0.03)$. Since the structure and content of the website were consistent and users were free to complete mission and participate in the AR game, the increase in pages reflected the increase in user participation. 


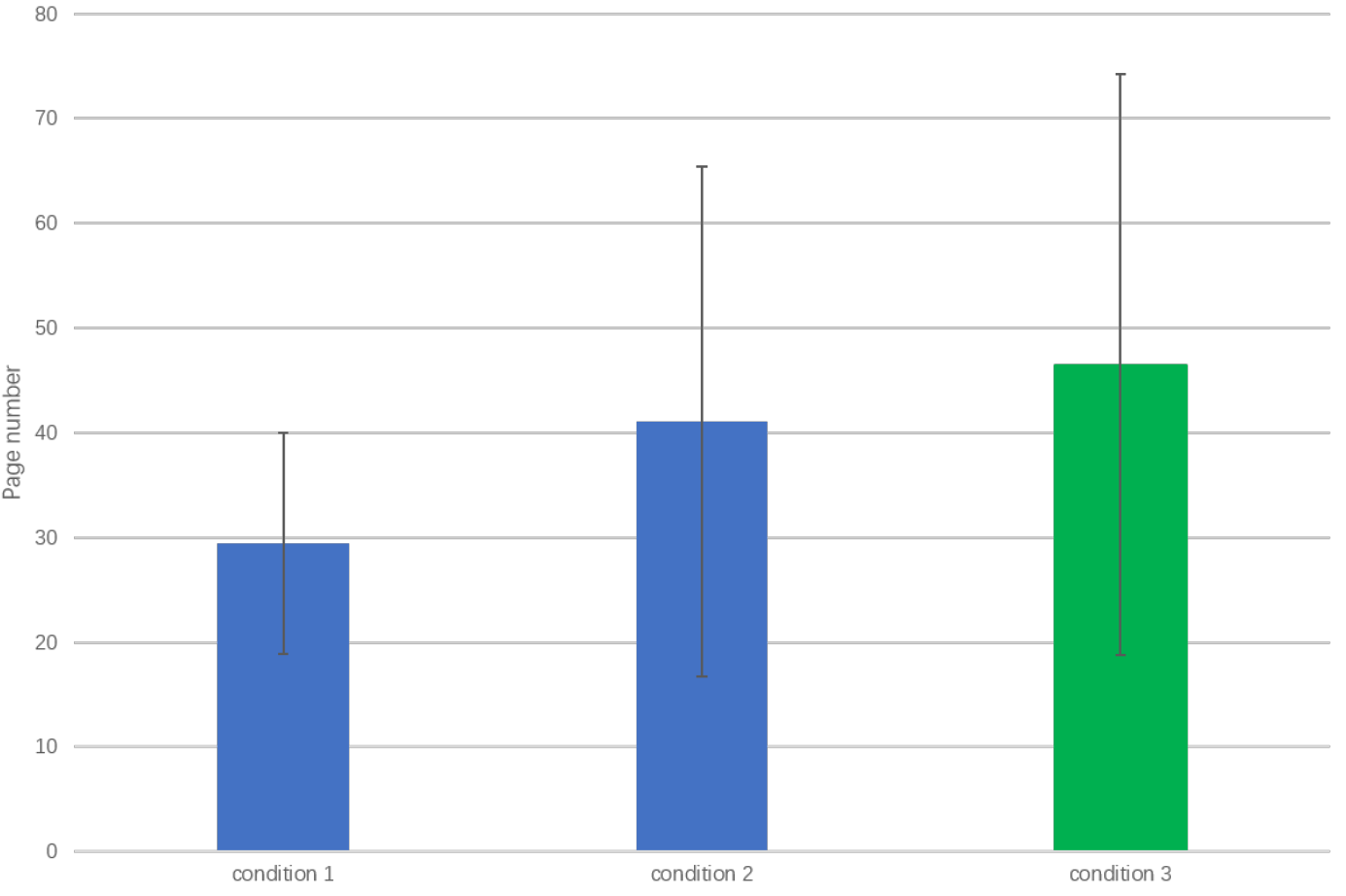

Figure 7. Average number of pages per session per person.

In experiment 1 , we did not take balance measures design (i.e., reversing the order of half the participants). We consider the practice effect (i.e., training effect) could be a problem in our experiment as the performance becomes better. As for practice effects, it will not only exist between the conditions but also within each condition because five-day experiment was conducted for each condition. Differences between conditions may come from the practice effect or the difference of conditions while the difference within the condition only comes from the practice effect. Therefore, we judge the impact of the practice effect within the condition. As shown in the Figure 8, we found not much practice effects within each condition in this case. Therefore, we think that we can believe that the significant difference mainly comes from different conditions rather than practice effects.

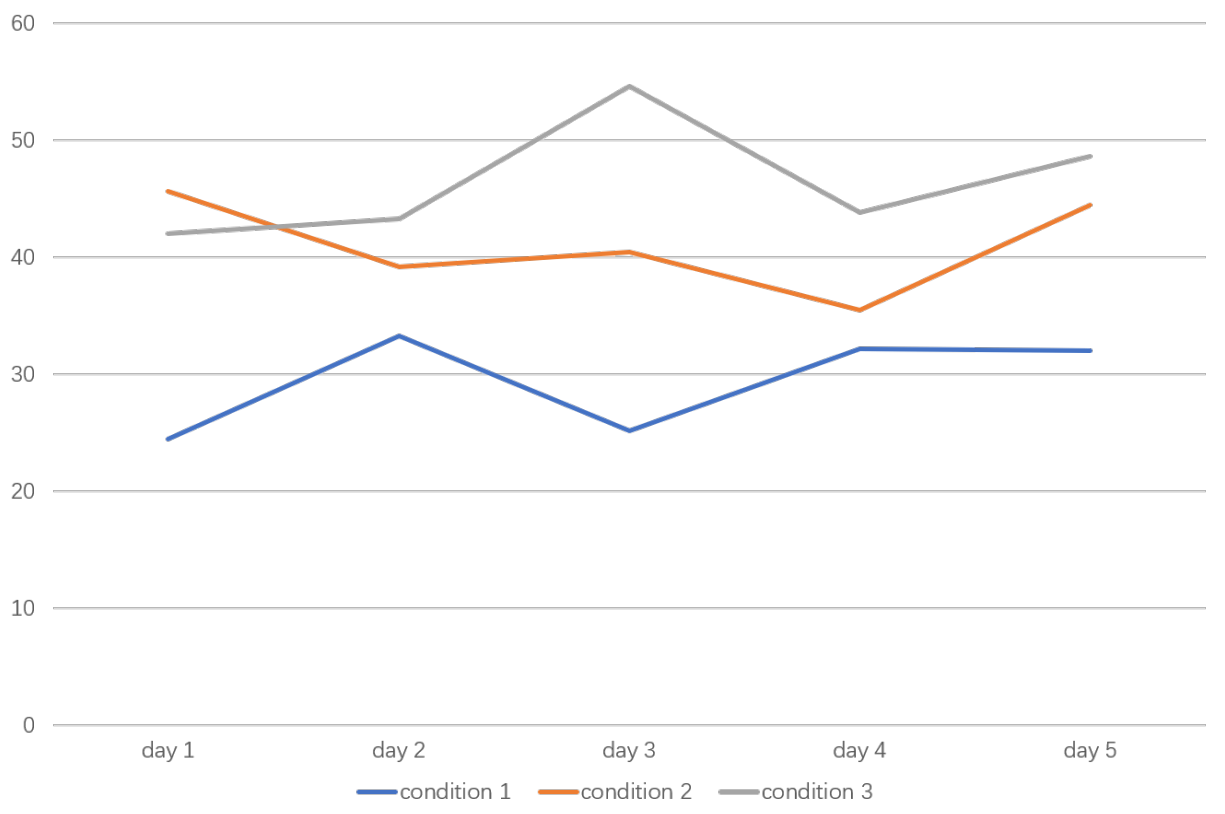

Figure 8. Changes in the average number of pages per session per person from day 1 to day 5. 


\section{Average Session Duration:}

Gaining an understanding of how much time people actually spend on the website has become an important user engagement metric [44]. The average session duration refers to the total time spent on the shopping website. It tracks all the activities that visitors complete on the website. In general, the longer the user spends on the shopping site, the higher the engagement.

In fact, we found that the average session duration gradually increased in conditions 2 and 3 , but this increase was not significant. One main reason is that users became more and more proficient in the content and structure of the website, so their browsing speed has increased.

\section{(2) Number Of Purchases:}

The above two indicators analyze the participation of shopping websites. For shopping websites, in addition to website participation, user purchases are also an important indicator of online shopping participation. We learned in detail about the changes in user purchases in the three conditions.

The number of items selected in the three conditions were recorded (see Figure 9). In condition 1 , each user selected an average of 16.3 items in one session ( $S D=6.5)$; in condition 2 , the number was 18.8 ( $\mathrm{SD}=7.5)$; and, in condition 3, the number was 23.7 (SD = 7.9). To understand what effect the game element had on purchases, we performed the paired t-test between conditions 1 and 2 . The results showed that there was no significant difference between conditions 1 and $2(p=0.11)$. However, there was a significant difference between conditions 2 and $3(p=0.001)$.

We continued to make comparisons of different kinds of purchased products. In condition 1 , each user selected an average of 0.8 environmentally friendly products, 1.4 local products, 1.5 healthy foods, and 12.6 other products in one session. In condition 2, each user selected an average of 2.1 environmentally friendly products, 4.7 local products, 2.9 healthy foods, and 9.1 other products in one session. In condition 3, each user selected an average of 3.3 environmentally friendly products, 5.7 local products, 3.8 healthy foods, and 10.9 other products in one session. By comparing conditions 1 and 2, we found that the purchase of three types of products increased, while the purchases of other products decreased; furthermore, the purchases of three kinds of products and other products increased in condition 3, compared to condition 2. Since users were free to choose products and there was no mandatory requirement for the completion of mission, the increase in number of items reflected the increase in user participation.

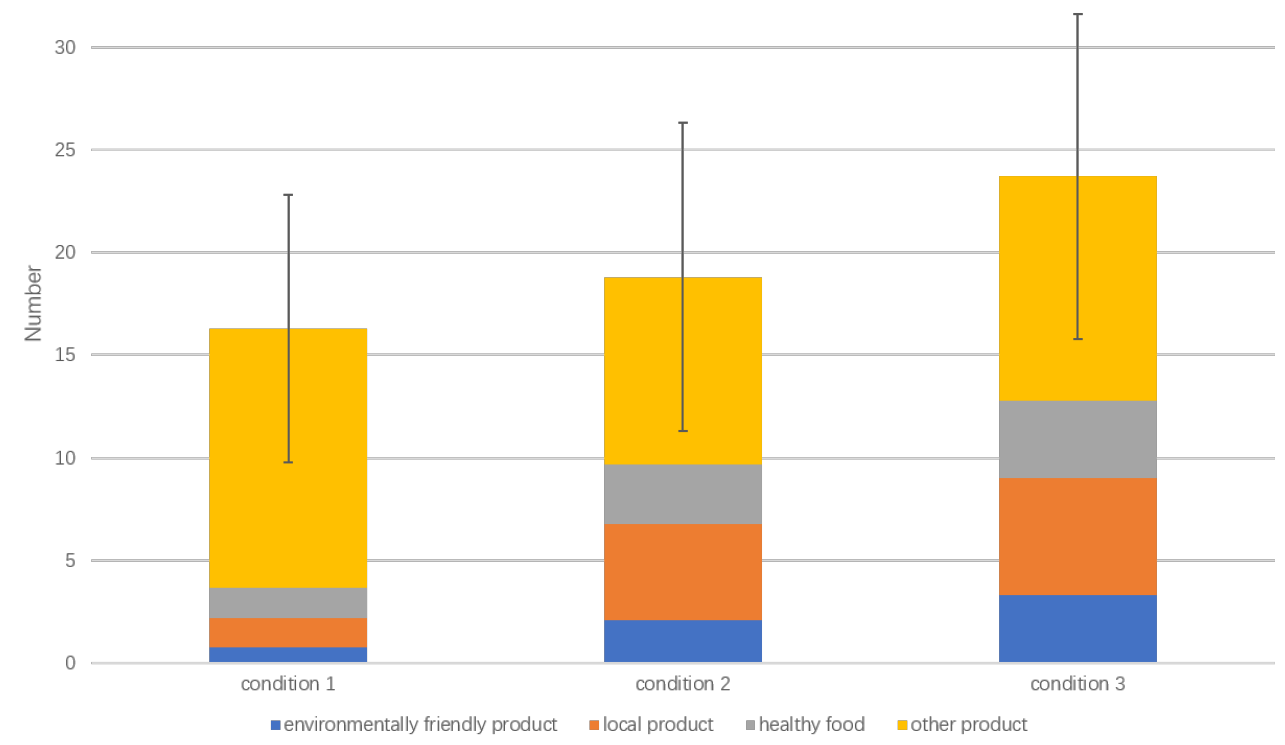

Figure 9. Average number of items purchased per person per session. 


\subsection{Experiment 2}

\subsubsection{Purpose}

In experiment 2, we explored how social cues (competitive and non-competitive interaction) affected the use of the system using a within-subjects design.

\subsubsection{Participants}

We invited another six student volunteers (three female) between the ages of 20 and 27 from the laboratory to participate in the online shopping simulation experiment $(\mathrm{M}=23.8)$. They were not informed in advance of the purpose of the experiment and the systems to be used. All participants had experience using the traditional point system and had played at least one multiplayer video game.

\subsubsection{Conditions}

Mission, text and AR-based feedback were included in all systems in experiment 2. In other words, all game elements in experiment 1 were included in experiment 2.

In condition 3, the system was the same as the system of condition 3 in experiment 1 . In condition 4 , the system enabled competitive interactions. In condition 4 , in addition to obtaining feedback from the AR-based feedback, users can compete with others through competitive interaction after shopping. In condition 5, the system enabled non-competitive interaction. In addition to obtaining feedback from the AR-based feedback, users can give virtual food away through non-competitive interaction after shopping. The order of conditions was randomized, following the counterbalanced measures design [47]. The experiment was carried out in a controlled setting environment. Since we did not give users external rewards in competitive and non-competitive interactions, we can compare groups to understand how social cues promote the use of the system.

To sum up, the only difference between condition 4 and condition 3 was whether there was a competitive interaction. The only difference between condition 5 and condition 3 was whether there was a non-competitive interaction. We expect that after adding social cues, users are willing to spend more time using the system.

\subsubsection{Procedure and Data Collection}

To conduct the study, six participants performed three conditions, each for five days. The shopping website and shopping process were the same as in experiment 1 . The introduction process before the experiment and the help provided by the researcher were the same as those in experiment 1 . Under all conditions, users were free to choose products, and there was no mandatory requirement for the completion of mission. The timer in Unity was activated to record the usage time of each function of the system in each condition.

\subsubsection{Results}

We summarize the experimental results under the three conditions and list them in Table 1. Under the three conditions, the mission and value point and pet interface of three systems were the same and users were free to use any interfaces. Therefore, the increase in system usage duration can prove that users were more willing to use the system. 
Table 1. Average time per person per session under each condition.

\begin{tabular}{cccc}
\hline Time (min) & Condition 3 & Condition 4 & Condition 5 \\
\hline Online shopping time & 11.52 & 17.38 & 19.30 \\
\hline Time (s) & & & \\
\hline Mission interface & 6.79 & 9.60 & 13.06 \\
Value point and pet interface & 12.14 & 15.94 & 20.60 \\
Competitive interaction interface & - & 23.97 & - \\
Non-competitive interaction interface & - & - & 18.31 \\
\hline
\end{tabular}

\section{(1) Competitive Interaction:}

The usage time of each interface (i.e., mission, value point and pet, and competitive interaction interface) of the system was recorded (see Figure 10). In condition 3, each user used the system for $18.93 \mathrm{~s}$ on average in one session ( $\mathrm{SD}=5.2)$; under condition 4 , the number was $49.51 \mathrm{~s}(\mathrm{SD}=8.8)$.

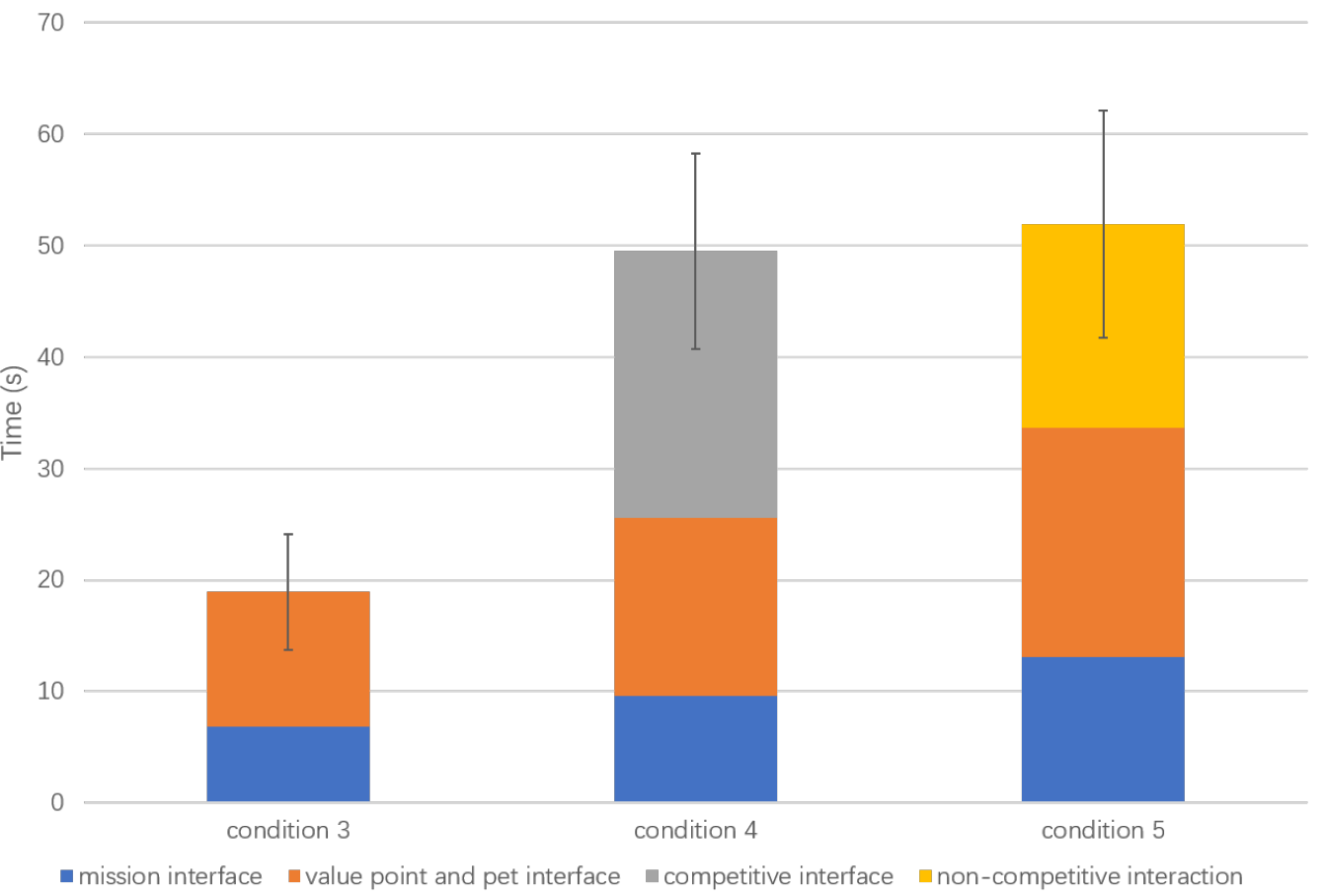

Figure 10. Average usage time of each interface per person per session.

We compared the mission interface and the value point and pet interface in conditions 3 and 4 . In condition 3, the average time spent by each user on the mission interface per session was $6.79 \mathrm{~s}$; under condition 4, it was $9.60 \mathrm{~s}$. In condition 3, the average time spent by each user on the value point and pet interface per session was $12.14 \mathrm{~s}$; under condition 4 , it was $15.94 \mathrm{~s}$. We performed a paired $\mathrm{t}$-test to compare changes under the two conditions. The results showed that there were significant differences between the mission interface under conditions 3 and $4(p=0.008)$. We also found that the time spent on the online shopping website increased in condition 4 .

\section{(2) Non-competitive Interaction:}

Similarly, we compared the usage time of each interface (i.e., mission, value point and pet, and non-competitive interaction interface) under conditions 3 and 5 (see Figure 10). In condition 5 , each user used the gamified point system for $51.98 \mathrm{~s}$ on average in one session ( $\mathrm{SD}=10.2)$.

We compared the mission interface and the value point and pet interface under conditions 3 and 5 . In condition 5, the average time each user spent on the mission interface per session was $13.06 \mathrm{~s}$ and the 
average time spent by each user on the value point and pet interface per session was $20.60 \mathrm{~s}$. A paired t-test was performed to compare the changes between conditions 3 and 5 . The results showed that, under conditions 3 and 5, there was a significant difference between the mission interface $(p=0.004)$, as well as between the value point and pet interface $(p=0.0004)$. We also observed that the time spent on online shopping website increased in condition 5 , compared to condition 3.

\section{(3) Competitive interaction vs. Non-competitive interaction:}

We compared conditions 4 and 5 to explore the effects of competitive and non-competitive interactions. A paired t-test was performed to compare the difference in total usage time of gamified point system between conditions 4 and 5 . The results showed that there was no significant difference in total usage time $(p=0.33)$.

\section{Summary of Results}

Based on the results of experiment 1, pet-based feedback was found to be effective at motivating users to participate and increasing their purchases, while the mission has a clear guiding effect on purchases. Generally, financial incentive is the factor that promotes user behavior change [48]. Our research proves that non-financial incentive can also be an important way to promote changes in user behavior [49].

According to the results of experiment 2, the usage of the same interface, and the time spent on shopping websites, improved significantly after adding social interactions. This indicates, to some extent, that the introduction of social interaction positively influences the use of the system and online shopping. By comparison of competitive and non-competitive interactions, we believe that both competitive and non-competitive interaction promotes the use of the gamified point system and that this difference is not significant, in terms of system usage duration.

\section{Discussion}

After experiment 2, two of the participants indicated that there was no reward if a pet wins in a competitive interaction. They suggested adding some feedback, such as winning several times to unlock an achievement or getting a reward for value points after winning. We compared the point system with non-financial incentives and the the point system without non-financial incentives to study the impact of non-financial incentives. We conclude that non-financial incentives can motivate users and influence their behavior. A very interesting future direction will be a comparison with financial incentives. The experimental plan is to add different levels of financial incentives into the traditional point system and compare them with the gamified point system, which could reveal to what extent these non-financial incentives prompt changes in user behavior.

There were some limitations, regarding this work: One limitation is with respect to the number of participants and their characteristics. The participants consisted only of six university students in each experiment, which limits the generalizability of the results. Future research may replicate this study by recruiting more participants of various age groups, gamer types (e.g., gamers and non-gamers), and people with different characteristics (e.g., environmentalists and non-environmentalists). People of different ages or who have different characteristics could have different motivations for using the system. It is important to understand what these goals are and to continue to redesign and redevelop features to get players involved in the system and continue shopping. Another limitation of this study was the mission design. In this study, we designed three predefined missions for users, rather than allowing them to freely choose different missions. We plan to improve the provision of missions to promote user motivation in a future study. One possible method is to create a mission list from which users can choose the mission that they are interested in. Another way is to provide personalized mission recommendations, such as considering user purchases and personal information. Users can choose characteristics before starting using the system (e.g., environmentalist or slimmer). If a user is an environmentalist, the system recommends missions related to the purchase of environmentally 
friendly products. If the purchase record shows that the user frequently purchases unhealthy foods, the system can give recommendations to encourage the purchase of healthy foods.

The short-term effects and long-term effects can be somewhat different since users are getting familiar with the experiment operation or get bored after the long-term experiment. In our research, we observed changes in users' shopping behavior in a five-day shopping in each condition. A common problem with these gamification studies is that user engagement will decrease in long-term experiments. Therefore, a reasonable inference is that as the experimental period increases, users' participation will be found to decrease. Compared to verifying it in long-term study, we believe that how to extend the sustained impact of gamified system is more important. We give the following suggestion to ensure the sustained impact of gamified point system, and provide some reference for the design of gamified system:

(1) The game can be continuously updated to provide new challenge to maintain long-term participation. Zhao et al. [50] found that the decrease in long-term engagement was observed to be reversible with periodic updates to the game. (2) The gamified system is intended to encourage people from the initial participation in activities to the establishment of new routines. In Lin et al.'s study [51], although most players' enthusiasm for the game decreased after the game's first two weeks, they found that individuals had, by that time, established new routines in their daily lives. Based on the above considerations, we can periodically update game features (i.e., mission, AR-based feedback and social cues) of the gamified point system in the initial use to maintain user participation over a period of time and finally establish their daily life patterns. The system can provide periodic changes of mission with different difficulty to provide new challenges. It could be an important way to ensure that gamified point systems or gamified systems promote long-term behavioral changes.

Shopping experiment is a simulated shopping experiment in the laboratory. The content purchased is daily commodities rather than expensive commodities. Although the participants were not required to spend their own money to purchase these products, they were required to choose the products of interest accordingly. Therefore, we believe that the results of the simulation experiment still have reference value.

We use AR display instead of the traditional display on the mobile phone screen. In related research, it was also found that gamified systems that use non-AR have an impact on the changes in user behavior. Therefore, we think that if we use non-AR displays in our system, we can still find changes in user behavior. However, due to the novelty of AR display components, there may be differences in the impact that users receive. We believe that in future research, comparing the same game content in different display (i.e., AR and non-AR) is of value to illustrate the importance of AR components.

In the current research, physical point cards are retained and used simultaneously with gamified point systems for AR-based interactions. With the development of mobile online loyalty programs, there will be a move towards the eradication of traditional cards, in favour of an electronic equivalent. Future research plans include the use of markerless AR to eliminate the dependency on physical point cards and focusing on the interaction between pets and users, as well as with the real environment.

\section{Conclusions}

While AR, gamification, and social factors are considered potential tools to increase user participation, how to incorporate these factors remains a difficult task. We explore a novel approach to integrate gamification and social interaction into a point system based on AR. We evaluated the gamified point system through experiments. Our research draws two main conclusions: (1) Gamification helps to increase user participation in online shopping; (2) Social cues (competitive and non-competitive interactions) motivate users to use the gamified point system.

Based on the above results, we believe that combining gamification and social interactions with marketing has a lot of potential, as they help to promote user engagement and influence user behavior. 
Author Contributions: B.L. and J.T. conceived the main idea; B.L. designed and implemented the system; B.L. performed the experiments. All authors have read and agreed to the published version of the manuscript.

Funding: This research received no external funding.

Acknowledgments: We would like to thank anonymous reviewers for their valuable comments and suggestions on the early revision of this paper. B.L. would like to thank the China Scholarship Council for sponsoring his study at the Waseda University.

Conflicts of Interest: The authors declare no conflict of interest.

\section{References}

1. Sharp, B.; Sharp, A. Loyalty programs and their impact on repeat purchase loyalty patterns. Int. J. Res. Mark. 1997, 14, 473-486. [CrossRef]

2. Dowling, G.R.; Uncles, M. Do customer loyalty programs really work? Sloan Manag. Rev. 1997, 38, 71-82.

3. Enzmann, M.; Schneider, M. Improving customer retention in e-commerce through a secure and privacy-enhanced loyalty system. Inf. Syst. Front. 2005, 7, 359-370. [CrossRef]

4. Leenheer, J.; Bijmolt, T.H.A. Which retailers adopt a loyalty program? An empirical study. J. Retail. Consum. Serv. 2008, 15, 429-442. [CrossRef]

5. Hupfeld, A.; Speed, C. Getting something for nothing?: A user-centric perspective on loyalty card schemes. In Proceedings of the 2017 CHI Conference on Human Factors in Computing Systems, Denver, CO, USA, 6-11 May 2017; pp. 4443-4453.

6. Lim, S.; Lee, B. Online loyalty programs viewed from a searchability perspective. In Proceedings of the 14th Annual International Conference on Electronic Commerce, ACM, New York, NY, USA, August 2012; pp. 255-262.

7. Gallo, A. The Value of Keeping the Right Customers. Harv. Bus. Rev. 2014, 29. Available online: https: //hbr.org/2014/10/the-value-of-keeping-the-right-customers (accessed on 12 August 2020).

8. Wright, C.; Sparks, L. Loyalty saturation in retailing: exploring the end of retail loyalty cards? Int. J. Retail. Distrib. Manag. 1999, 27, 429-440. [CrossRef]

9. McEachern, A. A History of Loyalty Programs, and How They Have Changed; Sweet Tooth Rewards: Kitchener, ON, Canada, 2014. Available online: https://blog.smile.io/a-history-of-loyalty-programs (accessed on 12 August 2020).

10. Magatef, S.G.; Tomalieh, E.F. The impact of customer loyalty programs on customer retention. Int. J. Bus. Soc. 2015, 6, 78-89.

11. Liu, B.; Tanaka, J. Ar-Based Point System for Game-Like Shopping Experience. In Proceedings of the 2018 International Conference on E-Business and Applications, Marina Del Rey, CA, USA, 23-25 February 2018; pp. 41-45.

12. Liu, B.; Tanaka, J. Gamified Point System Based on Mobile Devices. In Proceedings of the Twelfth International Conference on Advances in Computer-Human Interactions, Athens, Greece, 24-28 February 2019; pp. 174-180.

13. Liu, B.; Masuko, S.; Tanaka, J. Interactive point system supporting point classification and spatial visualization. In Human Interface and the Management of Information. Interaction, Visualization, and Analytics; Springer: Cham, Switzerland, 2018; pp. 78-89.

14. Rowley, J. Loyalty kiosks: Making loyalty cards work. Br. Food J. 2000, 102, 390-398. [CrossRef]

15. EagleEye. Plastic vs. Digital Loyalty Cards: Which is Best? 2017. Available online: https://www.eagleeye.c om/insights/blog/plastic-vs-digital-loyalty-cards-which-is-best (accessed on 26 February 2020).

16. Jayu Rewards Inc. Traditional vs. Digital Loyalty. Available online: http://jayurewards.com/traditional-vs -digital-loyalty/ (accessed on 27 February 2020).

17. Paula Thomas. Stamp Cards-Paper or Digital? 2018. Available online: http://www.liquidbarcodes.com/sti ll-using-stamp-cards / (accessed on 26 February 2020).

18. Cyr, D.; Head, M.; Ivanov, A. Design aesthetics leading to m-loyalty in mobile commerce. Inf. Manag. 2006, 43, 950-963. [CrossRef]

19. Erdoğmuş, İ.E.; Cicek, M. The impact of social media marketing on brand loyalty. Procedia-Soc. Behav. Sci. 2012, 58, 1353-1360. [CrossRef] 
20. Rauschnabel, P.A.; Rossmann, A.; tom Dieck, M.C. An adoption framework for mobile augmented reality games: The case of Pokémon Go. Comput. Hum. Behav. 2017, 76, 276-286. [CrossRef]

21. Pope, H. Introduction to Virtual and Augmented Reality. Libr. Technol. Rep. 2018, 54, 5-7.

22. Conaway, R.; Garay, M.C. Gamification and service marketing. SpringerPlus 2014, 3, 653. [CrossRef]

23. Dewber Ltd. Gamification and the Loyalty Programs. 2018. Available online: https://medium.com/@Dewb er/gamification-and-the-loyalty-programs-81f40d15f897 (accessed on 27 February 2020).

24. Hwang, J.; Choi, L. Having fun while receiving rewards?: Exploration of gamification in loyalty programs for consumer loyalty. J. Bus. Res. 2020, 106, 365-376. [CrossRef]

25. Kim, K.; Ahn, S.J.G. RETRACTED: The Role of Gamification in Enhancing Intrinsic Motivation to Use a Loyalty Program. J. Interact. Mark. 2017, 40, 41-51. [CrossRef]

26. Brad Davis. Why You Should Gamify Your Customer Loyalty Program (And How to Do It). 2018. Available online: https:/ / www.jeffbullas.com/gamify-loyalty-program/ (accessed on 28 February 2020).

27. Chen, Z.H.; Chou, C.Y.; Deng, Y.C.; Chan, T.W. Active open learner models as animal companions: Motivating children to learn through interacting with my-pet and our-pet. Int. J. Artif. Intell. Educ. 2007, 17, 145-167.

28. Liao, C.C.; Chen, Z.H.; Cheng, H.N.; Chen, F.C.; Chan, T.W. My-mini-pet: A handheld pet-nurturing game to engage students in arithmetic practices. J. Comput. Assist. Learn. 2011, 27, 76-89. [CrossRef]

29. Yang, J.C.; Chien, K.H.; Liu, T.C. A digital game-based learning system for energy education: An energy conservation pet. Turk. Online J. Educ.-Technol.-Tojet 2012, 11, 27-37.

30. Orl, B.; Ram, N.; Lang, D.; Houser, K.; Kling, N.; Coccia, M. Saving energy in an office environment: A serious game intervention. Energy Build. 2014, 74, 43-52.

31. Chen, Y.; Chen, Y.; riambelonoro, M.M.; Geissbuhler, A.; Pu, P. Design considerations for social fitness applications: Comparing chronically ill patients and healthy adults. In Proceedings of the 2017 ACM Conference on Computer Supported Cooperative Work and Social Computing, Portland, OR, USA, 25 February-1 March 2017; pp. 1753-1762.

32. Rokicki, M.; Chelaru, S.; Zerr, S.; Siersdorfer, S. Competitive game designs for improving the cost effectiveness of crowdsourcing. In Proceedings of the 23rd ACM International Conference on Conference on Information and Knowledge Management, Shanghai, China, 7 November 2014; pp. 1469-1478.

33. Li, W.; Grossman, T.; Fitzmaurice, G. Cadament: A gamified multi-player software tutorial system. In Proceedings of the SIGCHI Conference on Human Factors in Computing Systems, Toronto, ON, Canada, 26 April-1 May 2014; pp. 3369-3378.

34. Park, C.H.; Son, K.; Lee, J.H.; Bae, S.H. Crowd vs. crowd: Large-scale cooperative design through open team competition. In Proceedings of the 2013 Conference on Computer Supported Cooperative Work, San Antonio, TX, USA, 23-27 February 2013; 1275-1284.

35. Allen, C.; Pragantha, J.; Haris, D.A. 3 d virtual pet game "moar" with augmented reality to simulate pet raising scenario on mobile device. In Proceedings of the 2014 International Conference on Advanced Computer Science and Information System, Jakarta, Indonesia, 18-19 October 2014; pp. 414-419.

36. Hwang, G.J.; Wu, P.H.; Chen, C.C.; Tu, N.T. Effects of an augmented reality-based educational game on students' learning achievements and attitudes in real-world observations. Interact. Learn. Environ. 2016, 24, 1895-1906. [CrossRef]

37. Bai, Z.; Blackwell, A.F.; Coulouris, G. Exploring expressive augmented reality: The fingar puppet system for social pretend play. In Proceedings of the 33rd Annual ACM Conference on Human Factors in Computing Systems, Seoul, Korea, 18-23 April 2015 ; pp. 1035-1044.

38. Wetzel, R.; McCall, R.; Braun, A.K.; Broll, W. Guidelines for designing augmented reality games. In Proceedings of the 2008 Conference on Future Play: Research, Play, Share, Toronto, ON, Canada, 3-5 November 2008; pp. 173-180.

39. Jin, Q.; Wang, D.; Deng, X.; Zheng, N.; Chiu, S. AR-Maze: A tangible programming tool for children based on AR technology. In Proceedings of the 17th ACM Conference on Interaction Design and Children, Trondheim, Norway, 19-22 June 2018; pp. 611-616.

40. Bakker, N.C.; da Camara, J.R.; van Elsas, M.; Helsloot, L.J.; Spek, G.; van Baar, I.J.; Bidarra, R.; Kybartas, B.A. BloxAR: Augment your social life! In Proceedings of the First ACM SIGCHI Annual Symposium on Computer-Human Interaction in Play, Toronto, ON, Canada, 19-22 October 2014; pp. 319-322. 
41. Xie, J. Research on key technologies base Unity3D game engine. In Proceedings of the 20127 th International Conference on Computer Science \& Education, Melbourne, Australia, 14-17 July 2012; pp. 695-699.

42. Patil, P.P.; Alvares, R. Cross-platform Application Development using Unity Game Engine. Int. J. Adv. Res. Comput. Sci. Manag. Stud. 2015, 3.

43. UNG Compact. SDG Industry Matrix; KPMG: Amstelveen, The Netherlands, 2015.

44. Osman, M. Top 10 User Engagement Kpis to Measure. 2019. Available online: https:/ /www.searchenginejo urnal.com/content-marketing-kpis/user-engagement-metrics/\#close (accessed on 14 February 2020).

45. Boag, P. How to Measure Engagement on Your Website and Why Bother. 2019. Available online: https: / / boagworld.com/digital-strategy/measure-engagement/ (accessed on 15 February 2020).

46. Hsu, H.; Lachenbruch, P.A. Paired t test. Encycl. Biostat. 2005, 6. doi:10.1002/0470011815.b2a15112. [CrossRef]

47. Jensen, P. S.; Watanabe, H. K.; Richters, J. E. Who's up first? Testing for order effects in structured interviews using a counterbalanced experimental design. J. Abnormal Child Psychol. 1999, 27, 439-445. [CrossRef]

48. Kreis, H.; Mafael, A. The influence of customer loyalty program design on the relationship between customer motives and value perception. J. Retail. Consum. Serv. 2014, 21, 590-600. [CrossRef]

49. Marshall, M.; Harrison, S. Its about more than money: financial incentives and internal motivation. Qual. Saf. Health Care 2005, 14, 4-5. [CrossRef]

50. Zhao, Z.; Arya, A.; Whitehead, A.; Chan, G.; Etemad, S. Keeping Users Engaged through Feature Updates: A Long-Term Study of Using Wearable-Based Exergames. In Proceedings of the $2017 \mathrm{CHI}$ Conference on Human Factors in Computing Systems, Denver, CO, USA, 6-11 May 2017; pp. 1053-1064.

51. Lin, J.; Mamykina, L.; Lindtner, S.; Delajoux, G.; Strub, H. Fish'n'Steps: Encouraging physical activity with an interactive computer game. In Proceedings of the International Conference on Ubiquitous Computing, Orange County, CA, USA, 17-21 September 2006; pp. 261-278.

(C) 2020 by the authors. Licensee MDPI, Basel, Switzerland. This article is an open access article distributed under the terms and conditions of the Creative Commons Attribution (CC BY) license (http:/ / creativecommons.org/licenses/by/4.0/). 